\title{
Retention and Release of Copper on Montmorillonite As Affected by the Presence of a Pesticide
}

\author{
C. Maqueda,* T. Undabeytia, and E. Morillo
}

Instituto de Recursos Naturales y Agrobiología (CSIC), Apdo. 1052, 41080 Sevilla, Spain

\begin{abstract}
The effect of the cationic pesticide chlordimeform ( $N^{\prime}$-(4-chloro- 2 methylphenyl)- $N, N$-dimethylmethanimidamide hydrochloride) on adsorption-desorption processes of copper on to the clay mineral montmorillonite has been studied. This effect was evaluated when both adsorbates were adsorbed simultaneously and when the pesticide was previously adsorbed on montmorillonite. For different concentrations of pesticide used, copper adsorption decreases (in relation to pesticide-free treatment) when both adsorbates are adsorbed simultaneously, indicating a competition between both cation s for interlamellar possitions. In contrast, copper adsorption increases when the pesticide is previously adsorbed. Copper desorption isotherms show a very high hysteresis. The maximum percentage of copper desorbed is only $7 \%$, being lower when pesticide is present and decreasing with pesticide concentration.
\end{abstract}

Keywords: Adsorption; desorption; copper; pesticide; chlordim eform; montm orillonite

\section{INTRODUCTION}

The behavior of copper in soils is very important from both an agricultural and an environmental point of view. Copper is an essential element for plants and animals. An increase in its levels in soils, however, can inhibit organic matter biodegradation, as well as its subsequent nitrification. Furthermore, some animals are particularly sensitive to copper (Baker, 1990).

The supply of sewage sludge and/or animal manure (especially that of swine) to agricultural land, as well as the use of fungicides and algaecides containing copper, can represent an important source of pollution for this heavy metal.

The metal mobility in soils and its potential hazard depend mainly on the adsorption-desorption processes that can take place on the colloidal components. From the point of view of adsorption, clay minerals are the most important inorganic components in soils (Christensen, 1989). Their importance is due not only to their abundance but also to the high specific area and exchange capacity values. The addition of pesticides and organic fertilizers can affect copper adsorption by the clay fraction for several reasons, e.g., competition with the metal, chelation in solution, etc. (Puls et al., 1991; Madrid and Díaz-Barrientos, 1994; Morillo et al., 1994, 1997).

Although many studies have been published on the adsorption of pesticides and heavy metals independently, little attention has been given to the phenomena which take place when both are present together (Khan et al., 1980; Morillo and Maqueda, 1992; Morillo et al., 1994; Maqueda et al., 1994; Undabeytia et al., 1996; Grabec et al., 1996).

The objective of this study was to characterize copper adsorption-desorption on a clay mineral in the presence and absence of the cationic pesticide chlordimeform. The

* Author to whom correspondence should be addressed (telephone, 34-5-4624711; fax, 34-5-4624002; e-mail, celia@ irnase.csic.es).
Chart 1<smiles>Cc1cc(Cl)ccc1N=CN(C)C</smiles>

effect of the pesticide in $\mathrm{Cu}$ adsorption was studied when both adsorbates were adsorbed simultaneously and when the pesticide was previously adsorbed on montmorillonite.

\section{MATERIALS AND METHODS}

The clay mineral used was a montmorillonite from Arizona, designed SAZ-1 (Van Olphen and Fripiat, 1979), supplied by the Clay Mineral Society. Its cation exchange capacity (CEC) is 123.5 mequiv/100 g, of which 100.8 mequiv are due to $\mathrm{Ca}^{2+}$, 19.2 mequiv to $\mathrm{Mg}^{2+}, 2.6$ mequiv to $\mathrm{Na}^{+}$, and 0.9 mequiv to $\mathrm{K}^{+}$.

Technical grade chlordimeform (90\% purity), supplied by Schering Agro, S.A., was used. This pesticide is soluble in water (50\% by weight) and ionizes completely, giving the chlordimeform cation and chloride anion. The molecular structure of chlordimeform hydrochloride is shown in Chart 1 .

The adsorption experiments were done in triplicate in 50$\mathrm{mL}$ polypropylene centrifuge tubes, by mixing $0.1 \mathrm{~g}$ of clay mineral with $20 \mathrm{~mL}$ of $0.01 \mathrm{M} \mathrm{NaCl}$ solutions containing various concentrations of chlordimeform and/or $\mathrm{Cu}$ (II). The concentrations used were $0.3,0.5$, and $1.0 \mathrm{mM}$ for chlordimefor $\mathrm{m}$ and $5-30 \mathrm{mg} \mathrm{L}^{-1}$ for copper solutions. The samples were shaken for $24 \mathrm{~h}$ at $20 \pm 1{ }^{\circ} \mathrm{C}$. The amounts of chlordimeform and $\mathrm{Cu}$ (II) adsorbed were calculated as the differences between their concentrations before and after equilibrium. The concentration of chlordimeform was determined spectrophotometrically at $240 \mathrm{~nm}$ and $\mathrm{Cu}$ (II) by atomic absorption spectrometry (AAS). The inorganic cations $\mathrm{Ca}^{2+}$ and $\mathrm{Mg}^{2+}$ released during chlordimeform or/and $\mathrm{Cu}$ adsorption were determined by AAS.

Successive adsorptions ( $\mathrm{Cu}(\mathrm{II})$ after chlordimeform) were achieved by mixing $0.1 \mathrm{~g}$ of clay mineral with $20 \mathrm{~mL}$ of 0.01 $\mathrm{M} \mathrm{NaCl}$ solutions containing various concentrations of chlor- 
Copper Sorption/Desorption on Montmorillonite

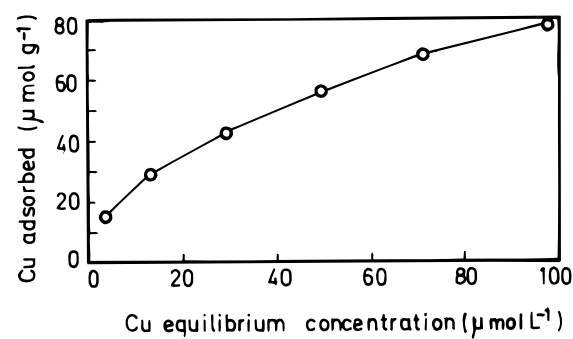

Figure 1. Adsorption is otherm of $\mathrm{Cu}$ (II) on montmorillonite.

dimeform. The samples were shaken for $24 \mathrm{~h}$ at $20 \pm 1{ }^{\circ} \mathrm{C}$. After reaching equilibrium, the suspensions were centrifuged, the supernatant was removed, and the solid samples were washed twice with distilled water and treated again with $\mathrm{Cu}$ (II) solutions under the same conditions as previously.

The adsorption isotherms were obtained by plotting the amount of $\mathrm{Cu}$ adsorbed $C_{\mathrm{s}}\left(\mu \mathrm{mol} \mathrm{g}^{-1}\right)$ versus the equilibrium concentration $C_{\mathrm{e}}\left(u \mathrm{~mol} \mathrm{~L}^{-1}\right)$. In all cases, the $\mathrm{pH}$ of the equilibrium solutions from simultaneous and successive adsorptions was $6.5 \pm 0.1$.

Desorption experiments were performed after equilibrium adsorption was reached, by removing half of the supernatant after centrifugation, replacing it with $10 \mathrm{~mL}$ of $0.01 \mathrm{M} \mathrm{NaCl}$, allowing equilibration for an additional 24-h period, and subsequently continuing as in the adsorption experiment. This process was repeated twice more. The time-dependence (kinetic) study of the adsorption and desorption experiments indicated that the time of $24 \mathrm{~h}$ was long en ough for reaching the equilibrium. The desorption isotherms were obtained by plotting the amount of $\mathrm{Cu}$ that remained adsorbed $\left(\mu \mathrm{mol} \mathrm{g}^{-1}\right)$ versus the final concentration $\left(\mu \mathrm{mol} \mathrm{L}^{-1}\right)$ for every desorption process.

\section{RESULTS AND DISCUSSION}

Adsorption of Copper in the Absence of Chlordimeform. The adsorption isotherm of $\mathrm{Cu}$ (II) on montmorillonite is shown in Figure 1. This isotherm corresponds to the L-type according to Giles et al. (1960). The shape of this isotherm indicates that as sites are filled it becomes increasingly more difficult for adsorbate to find a vacant site. The adsorption of metal ions by layer silicates and other adsorbents may occur in different types of surface sites, the higher energy sites being occupied within the lower range of surface coverage (Inskeep and Baham, 1983; García-Miragaya et al., 1986; Madrid et al., 1991). In the case of montmorillonite, this can be expected to occur on variable charge edge sites of high energy and through exchange with the exchangeable cations ( $\mathrm{Ca}$ and $\mathrm{Mg}$ principally) saturating the permanent charge planar sites.

The species concentrations of copper in solution for our system ( $\mathrm{pH}$ 6.5), estimated by using the equilibrium constants given by Lindsay (1979), are $91.64 \% \mathrm{Cu}^{2+}$, $5.93 \% \mathrm{CuOH}^{+}$, and $2.44 \% \mathrm{CuCl}^{+}$. The species $\mathrm{CuCl}_{2}$ and $\mathrm{CuCl}_{3}{ }^{-}$represent a very low proportion (below $0.01 \%)$. Although copper adsorption possibly occurs principally through the $\mathrm{Cu}^{2+}$ species, the possibility of surface hydrolysis should be taken in to account (Harsch and Doner, 1984).

To determine if only $\mathrm{Cu}^{2+}$ species was adsorbed on the clay, the amount of $\mathrm{Ca}$ and $\mathrm{Mg}$ desorbed was plotted versus the amount of $\mathrm{Cu}$ adsorbed in microequivalents per gram, a straight line with a slope of 0.75 being obtained. This value differs from the theoretical value of 1 that would be obtained if all the copper were adsorbed as $\mathrm{Cu}^{2+}$ by cation exchange. This discrepancy can be attributed in part to surface hydrolysis onto the clay, to adsorption of $\mathrm{Cu}$ onto edge positions, and also
J. Agric. Food Chem, Vol. 46, №. 3, 19981201
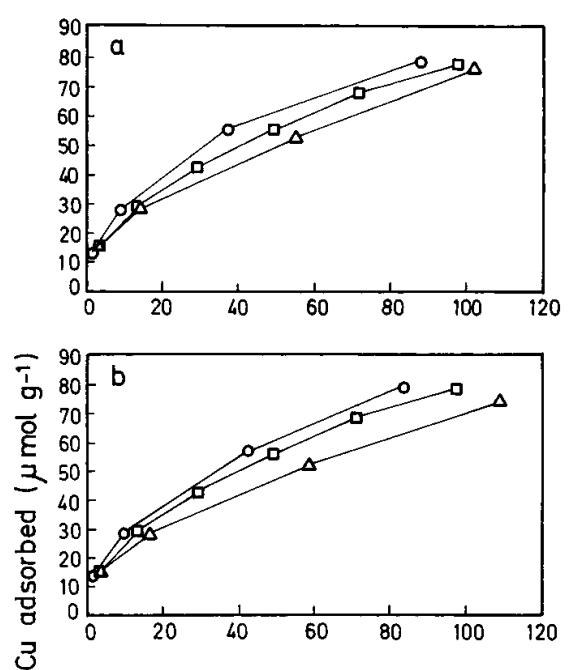

3

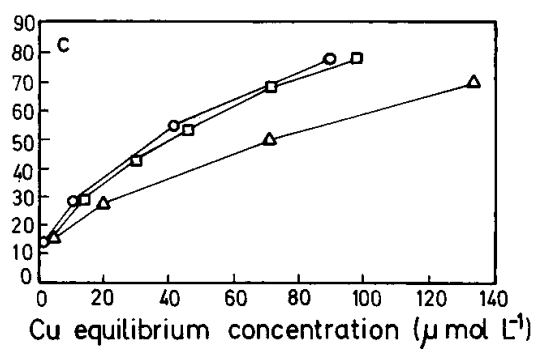

Figure 2. Adsorption is otherms of $\mathrm{Cu}$ (II) on montmorillonite from chlordimeform-free solutions $(\square)$, in comparison with simultaneous $(\triangle)$ and successive $(\bigcirc) \mathrm{Cu}$ adsorption, at various chlordimeform concentrations: 0.3 (a), 0.5 (b), and 1.0 (c) $\mathrm{mM}$.

to the adsorption of other than $\mathrm{Cu}^{2+}$ species. Stadler and Schindler (1993) modeled $\mathrm{Cu}$ adsorption onto montmorillonite, observing that at $\mathrm{pH}$ values greater than 5.5 copper adsorption was explained taking into account the reaction of the metal with the aluminol groups, principally by the formation of the $\mathrm{AlOCuOH}$ species. Thus it appears that the adsorption of copper occurs principally by adsorption of the $\mathrm{Cu}^{2+}$ species onto interlayer positions; and as $\mathrm{Cu}^{2+}$ or its hydroxylated form onto edge positions.

Adsorption of Copper in the Presence of Chlordimeform. Figure 2 shows the adsorption isotherm of copper on montmorillonite from chlordimeform-free solution in comparison with copper adsorption in the presence of different pesticide concentrations $(0.3,0.5$, and $1.0 \mathrm{mM}$ ). It is observed that copper adsorption decreases when the pesticide concentration increases, suggesting a competition with the pesticide for the adsorption sites. Only the point for the lowest copper concentration seems to be independent of the pesticide concentration. This can be explained by the fact that at low copper concentration it is adsorbed on high affinity sites on edge positions. The pesticide does not compete for these positions. Pesticide competition at the lower pesticide concentration has less effect on $\mathrm{Cu}$ adsorption than on $\mathrm{Zn}$ adsorption (Morillo and Maqueda, 1992), indicating a higher preference of this clay mineral for $\mathrm{Cu}$ than for $\mathrm{Zn}$.

Copper adsorption by montmorillonite can be described by the Freundlich adsorption equation $(r>0.99$, $p<0.01)$, the linear form of which is

$$
\log C_{\mathrm{s}}=\log K_{\mathrm{f}}+n \log C_{\mathrm{e}}
$$

where $C_{\mathrm{s}}$ is the amount of adsorbed $\mathrm{Cu}\left(\mu \mathrm{mol} \mathrm{g} \mathrm{g}^{-1}\right)$ and 
Table 1. Freundlich Constants and Correlation Coefficients for Cu Adsorption on Montmorillonite in the Absence and Presence of Chlordimeform

\begin{tabular}{cccc}
\hline clordimeform, $\mathrm{mM}$ & $K_{\mathrm{f}}$ & $n$ & $r$ \\
\hline 0.0 & 240 & 0.49 & 0.99 \\
0.3 & 204 & 0.46 & 0.99 \\
0.5 & 174 & 0.46 & 0.99 \\
1.0 & 155 & 0.43 & 0.99
\end{tabular}

Table 2. Freundlich Constants and Correlation Coefficients for Cu Adsorption on Montmorillonite in the Absence of Chlordimeform and When the Clay Is Previously Treated with the Pesticide

\begin{tabular}{cccc}
\hline chlordimefor, $\mathrm{mM}$ & $K_{\mathrm{f}}$ & $n$ & $r$ \\
\hline 0.0 & 240 & 0.49 & 0.99 \\
0.3 & 276 & 0.47 & 0.99 \\
0.5 & 260 & 0.54 & 0.99 \\
1.0 & 246 & 0.53 & 0.99
\end{tabular}

$C_{\mathrm{e}}$ the $\mathrm{Cu}$ concentration $\left(\mathrm{mmol} \mathrm{L}^{-1}\right)$ in the equilibrium solution. $K_{\mathrm{f}}$ denotes the amount of $\mathrm{Cu}$ adsorbed at an equilibrium concentration of $1 \mathrm{mmol} \mathrm{L}^{-1}$. This constant $\left(K_{\mathrm{f}}\right)$ is a measure of the relative adsorption capacity, and $n$ gives an idea of the adsorption intensity.

The values obtained for these two constants are listed in Table 1. The competition of the pesticide on $\mathrm{Cu}$ adsorption is reflected by the diminishing $K_{\mathrm{f}}$ values as pesticide concentration increases, from 240 to 155 for the systems in the absence and presence of the higher pesticide concentration

To determine the effect of the pesticide previously adsorbed on the clay on $\mathrm{Cu}$ adsorption, an experiment was performed in which montmorillonite was previously treated with various chlordimeform concentrations. After reaching equilibrium, the solution was removed and the sample was washed twice with distilled water prior to subsequent treatment with $\mathrm{Cu}$. It was observed that $\mathrm{Cu}$ adsorption was higher when the clay was previously treated with the pesticide than in the adsorption from pesticide-free solutions or when both adsorbates were added simultaneously. This may be due to the fact that a great part of the pesticide is adsorbed on planar positions in the clay, opening the layers and making easier the subsequent penetration of copper. This behavior is possible only when the amount of chlordimeform adsorbed is much lower than the cationic exchange capacity of the mineral, and so a very small fraction of interlamellar positions are occupied by the pesticide, the other positions being available for copper adsorption.

Table 2 shows the Freundlich parameters for $\mathrm{Cu}$ adsorption isotherms when the pesticide is previously adsorbed on the clay. In this case the pesticide had a less marked effect on $\mathrm{Cu}$ adsorption, showing little dependence upon the pesticide concentration. The slight differences between $K_{\mathrm{f}}$ values support these observations. As in the case of adsorption of Cd (Undabeytia et al., 1996) the greatest $\mathrm{Cu}$ adsorption occurs when the pesticide is previously adsorbed on the clay, in contrast to the behavior described previously when montmorillonite is treated simultaneously with copper and the pesticide.

A useful parameter to measure the adsorbantadsorbate affinity is the distribution coefficient $K_{\mathrm{D}}$, which is defined as

$$
K_{\mathrm{D}}=\frac{[\text { X-clay }]}{[\text { X-solution }]}
$$
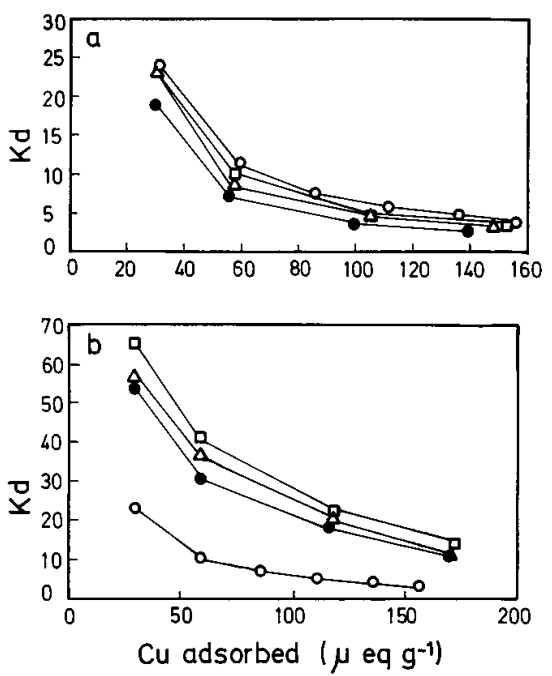

Figure 3. $\mathrm{Cu}$ (II) $K_{\mathrm{D}}$ values as function of the amount of $\mathrm{Cu}$ adsorbed in simultaneous (a) and successive (b) adsorption at various chlordimefor $m$ concentrations: $0(\bigcirc), 0.3(\square), 0.5$ $(\triangle)$, and $1.0(\bullet) \mathrm{mmol} \mathrm{L}^{-1}$

where the numerator is the sorbate concentration adsorbed on the clay, and the denominator is the sorbate concentration in the equilibrium solution, both expressed in microequivalents per gram.

To calculate $K_{\mathrm{D}}$ for copper it was assumed that this heavy metal is in solution in the form of $\mathrm{Cu}^{2+}$, since the proportion of this species is $>90 \%$.

Figure 3 shows the $K_{\mathrm{D}}$ values for copper adsorption at variou s chlordimeform concentrations $(0,0.3,0.5$, and $1 \mathrm{mM})$. Figure 3 a represents the values when the clay mineral is treated simultaneously with the pesticide and Figure $3 \mathrm{~b}$ when montmorillonite is previously treated with the pesticide. In all cases there are high $K_{\mathrm{D}}$ values for low surface coverage; these decrease when the loading of the metal is higher. The affinity of $\mathrm{Cu}$ for the adsorbent decreases until an almost constant value is reached. This could indicate again that in all cases sites of high affinity play an important role at low surface coverage.

In simultaneous adsorption (Figure $3 \mathrm{a}$ ), $K_{\mathrm{D}}$ values decrease as pesticide concentrations increase due to the higher competition of the pesticide especially for interlamellar positions. On the other hand, when the pesticide is previously adsorbed on montmorillonite (Figure $3 \mathrm{~b}$ ), $K_{\mathrm{D}}$ values are very similar for each pesticide concentration due to the scarce competition between both sorbates, since in successive adsorption of $\mathrm{Cu}$ (II) the chlordimeform concentration present in equilibrium solution is very low, because it is only a small amount of that previously adsorbed on the clay which has been desorbed. In all cases the $K_{\mathrm{D}}$ values are always higher than the corresponding values when $\mathrm{Cu}$ is adsorbed in the absence of the pesticide. This is in agreement with the results obtained in Figure 2, showing the higher adsorption of $\mathrm{Cu}$ on montmorillonite previously treated with chlordimeform, and indicates the higher affinity of $\mathrm{Cu}$ for montmorillonite when the pesticide has been previously adsorbed.

Desorption Processes. Figure 4 shows the adsorption isotherms of $\mathrm{Cu}$ from chlordimeform-free solutions in comparison with simultaneous and successive $\mathrm{Cu}$ adsorption when the concentration of pesticide was 1 $\mathrm{mM}$ and the consecutive three-step desorption isotherms. 

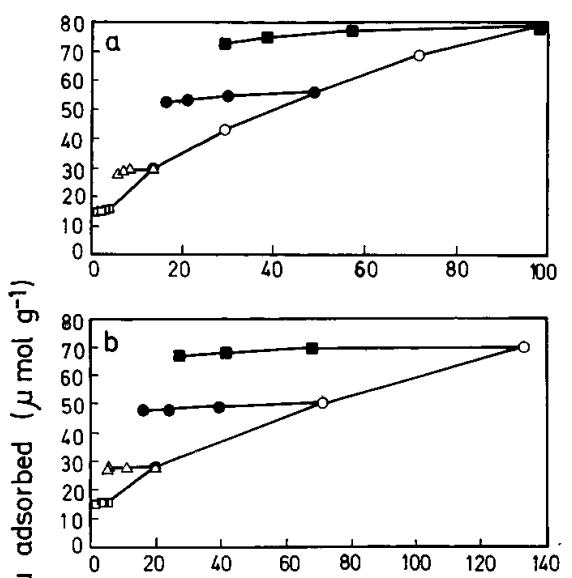

ठ

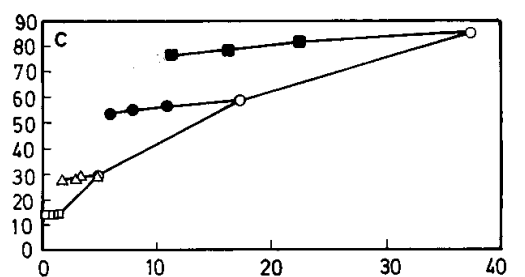

$\mathrm{Cu}$ equitibrium concentration $\left(\mu \mathrm{mol} \mathrm{L}^{-1}\right)$

Figure 4. Adsorption-desorption isotherms of $\mathrm{Cu}$ on montmorillonite from chlordimeform-free solutions (a) and in the presence of $1 \mathrm{mM}$ chlordimeform: (b) simultaneous and (c) successive.

In all cases a very high hysteresis is observed; i.e., the results of desorption deviated markedly from those corresponding to the adsorption isotherms. This hysteresis indicates that the adsorption is virtually nonreversible, since the amount of copper that remains adsorbed for each desorption point is practically the same. The desorption cycles involve centrifugation, removal of half of the volume of the supernatant, and addition of a corresponding volume of $10 \mathrm{~mL}$ of $0.01 \mathrm{~N}$ $\mathrm{NaCl}$, and thus the concentrations of $\mathrm{Ca}^{2+}$ and $\mathrm{Mg}^{2+}$ cations in suspension are reduced. A small increase in the magnitude of the surface potential (Undabeytia, 1997), due to a smaller sum of total concentrations of divalent cations, contributes to enhanced adsorption of $\mathrm{Cu}$ in desorption cycles, as occurs in $\mathrm{Cd}$ desorption process on montmorillonite (Undabeytia et al., 1997b).

Figure 5 shows the percentage of copper desorbed versus the initial amount of copper used. The maximum percentage desorbed after three cycles of desorption is only $7 \%$ of the $\mathrm{Cu}$ previously adsorbed, corresponding to the pesticide-free isotherm, being lower when the pesticide is present and decreasing with pesticide concentration. This indicates that the increasing pesticide concentration in some way impedes the metal desorption. In general, for a given concentration of pesticide the amount of $\mathrm{Cu}$ desorbed was smaller for the lower concentration of $\mathrm{Cu}$, possibly due to the fact that when low amounts are adsorbed the copper is adsorbed principally on edge positions, from which it cannot be desorbed by cationic exchange. At higher adsorption densities the interlamellar positions have more importance and desorption from them is easier, since they are not high affinity positions. Consequently the heterogeneity of adsorption sites affects the adsorption process and hysteresis is likely to be associated with the different paths of the adsorption and desorption processes.
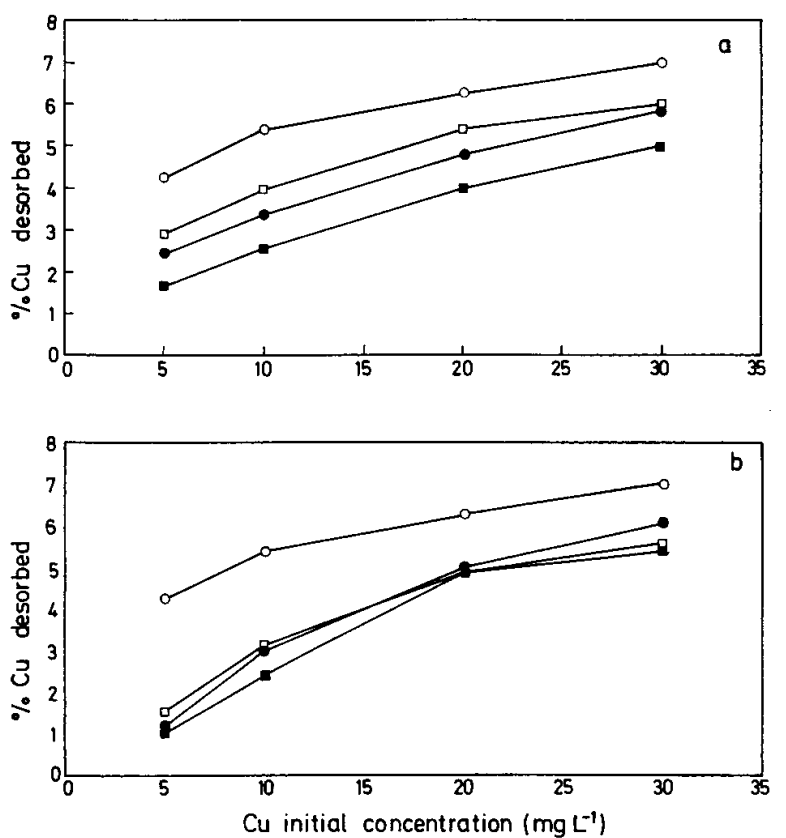

Figure 5. Percentages of $\mathrm{Cu}$ (II) desorbed versus the initial amounts of $\mathrm{Cu}$ used in simultaneous (a) and successive (b) adsorption, at various chlordimeform concentrations: $0(\mathrm{O})$, $0.3(\square), 0.5(\bullet)$ and $1.0(\mathbf{\square}) \mathrm{mM}$.

$\mathrm{Cu}$ desorption experiments carried out with the clay mineral previously treated with the pesticide (successive adsorption) show (Figure 5b) that the amount of desorbed metal is a little lower than in the absence of the pesticide, as occurs when copper and pesticide are adsorbed simultaneously. In successive adsorptions the percentages of copper desorbed are very similar and almost independent of the pesticide concentration with which the clay was previously treated, since the cations which are desorbing copper are principally those from the background electrolite, because the chlordimeform concentration in equilibrium solution is very low (it is only a small fraction of pesticide desorbed from the clay).

For the lower metal concentration s (5 and $10 \mathrm{mg} \mathrm{L}^{-1}$ ), the percentages of $\mathrm{Cu}$ desorption are lower in successive adsorptions than in simultan eous adsorption (Figure 5). This may be due to the greater affinity for copper adsorption in succesive processes, as was shown for the higher $K_{\mathrm{D}}$ values obtained in successive than in simultaneous adsorption, for lower surface coverage (Figure 3).

The experiments carried out in this work show that, given the mutual influence between pesticides and heavy metals in adsorption-desorption processes, these phenomena must be taken into account if they are to be applied rationally.

\section{LITERATURE CITED}

Baker, D. E. Copper. In Heavy Metals in Soils; Alloway, B. J ., Ed.; Blackie: Glasgow, 1990; pp 151-176.

Christensen, T. H. Cadmium soil sorption at low concentrations. VIII. Correlation with soil parameters. Water, Air, Soil Pollut. 1989, 44, 71-82.

García-Miragaya, J .; Cárdenas, R.; Page, A. L. Surface loading effect on $\mathrm{Cd}$ and $\mathrm{Zn}$ sorption by kaolinite and montmorillonite from low concentration solutions. Water, Air, Soil Pollut. 1986, 27, 181-190.

Giles, G. H.; McEvan, T. H.; Nekhwa, S. N.; Smith, D. Studies in adsorption: XI. A system of classification of solution adsorption isotherm and its use in diagnosis of adsorption 
mechanisms and measurement of specific surface area of solids. J. Chem. Soc. 1960, 3973-3993.

Grabec, I.; Ogorevc, B.; Hudnik, V. A methodological approach to the application of a vermiculite modified carbon paste electrode in interaction studies: Influence of some pesticides on the uptake of $\mathrm{Cu}$ (II) from a solution to the solid phase. Fresenius J. Anal. Chem. 1996, 354, 770-773.

Harsch, J. B.; Doner, H. E. Specific adsorption of copper on an hydroxy-aluminium-montmorillonite complex. Soil Sci. Soc. Am.J. 1984, 48, 1034-1039.

Inskeep, W. P.; Baham, J. Adsorption of Cd (II) and Cu (II) by $\mathrm{Na}$-montmorillonite at low surface coverage. Soil Sci. Soc. Am. J. 1983, 47, 660-665.

Khan, S.; Khan, N. N.; Iqbal, N. Studies on the effects of some organic pollutants in the heavy metal transport in an Indian soil. Environ. Pollut. 1980, 70, 109-115.

Lindsay, W. L. Chemical Equilibria in Soils; Wiley: New York, 1979.

Madrid, L.; Díaz-Barrientos, E.; Contreras, M. C. Relationships between zinc and phosphate adsorption on montmorillonite and an iron oxyhydroxide. Aust.J.S oil Res. 1991, 29, 239277.

Madrid, L.; Díaz-Barrientos, E. Retention of heavy metals by soils in the presence of a residue from the olive oil industry. Eur. J. Soil Sci.1994, 45 (1), 71-77.

Maqueda, C.; Morillo, E.; Undabeytia, T. Behaviour of chlormequat adsorption on montmorillonite in the presence of copper. In Environmental Behaviour of Pesticides and Regulatory Aspects; Copin, A., Honins, G., Pussemier, L., Salembier J. F., Eds.; European Study Service: Brussels, 1994; pp 179-183.

Morillo, E.; Maqueda, C. Simultaneous adsorption of chlordimeform and zinc on montmorillonite. Sci. Total Environ. 1992, $123 / 124,133-143$.
Morillo, E.; Maqueda, C.; Bejarano, M.; Madrid, L.; Undabeytia, T.Cu(II)-glyphosate system: a study by anodic stripping voltammetry and the influence on $\mathrm{Cu}$ adsorption by montmorillonite. Chem osphere 1994, 28, 2185-2196.

Morillo, E.; Undabeytia, T.; Maqueda, C. Adsorption of glyphosate on the clay mineral montmorillonite: effect of $\mathrm{Cu}$ (II) in solution and adsorbed on the mineral. Environ. Sci. Technol. 1997, 31, 3588-3592.

Puls, R. W.; Powell, R. M.; Clark, D.; Eldred, L. J. Effect of $\mathrm{pH}$, solid/solution ratio, ionic strength, and organic acids on $\mathrm{Pb}$ and $\mathrm{Cd}$ sorption on kaolinite. Water, Air Soil Pollut. 1991, 54-58, 423-430.

Stadler, M.; Schindler, P. W. Modelling of $\mathrm{H}^{+}$and $\mathrm{Cu}^{2+}$ adsorption on Ca-montmorillonite. Clays Clay Miner. 1993, $41,288-296$

Undabeytia, T. Estudio de la competencia de plaguicidas y metales pesados en suelos y su fracción coloidal. (Study of the competence of pesticides and heavy metals in soils and their colloidal fraction.) Ph.D. Dissertation, The University of Seville, Spain, 1997.

Undabeytia, T.; Morillo, E.; Maqueda, C. Adsorption of Cd and $\mathrm{Zn}$ on montmorillonite in the presence of a cationic pesticide. Clay Miner. 1996, 31, 485-490.

Undabeytia, T.; Nir, S.; Rytwo, G.; Morillo, E.; Maqueda, C. Modeling adsorption-desorption processes of $\mathrm{Cd}$ on montmorillonite. Clays Clay Miner., in press.

Van Olphen, H.; Fripiat, J. J. Eds. Data Handbook for Clay Materials and other Nonmetallic Minerals; Pergamon: Oxford, U.K., 1979.

Received for review June 9, 1997. Revised manu script received December 5, 1997. Accepted December 19, 1997.

JF970500K 